\title{
Taking Others into Account: Self-Interest and Fairness in Majority Decision Making
}

\author{
Jan Sauermann University of Cologne \\ André Kaiser University of Cologne
}

\begin{abstract}
Research on the formal properties of democratic aggregation mechanisms has a long tradition in political science. Recent theoretical developments, however, show that in the discussion of normative contents of democratic decisions, the actual shape of preferences deserves just as much attention. However, our knowledge about the concrete motivations of individual behavior in democratic decisions is incomplete. Using laboratory experiments, this article examines the existence of social preferences in majority decisions. Contrary to earlier experiments of committee decision making, we develop a design that controls for the conditions of communication and the level of information between subjects. This allows us to comparatively test the predictive power of several theories. We find strong evidence that self-interest and fairness motivate human behavior in majority decisions.
\end{abstract}

 he question of what motivates individual behavior in social interactions is central for a better understanding of democratic decision making. Do individuals selfishly maximize their own material welfare, or do they take the well-being of others into account? There is a wealth of experimental evidence that such social preferences play an important role in all sorts of games (see Fehr and Fischbacher 2002). Individuals display other-regarding behavior, considering distributional consequences of their choices. Furthermore, several models of individual behavior incorporate these experimental findings (e.g., Bolton and Ockenfels 2000; Charness and Rabin 2002; Fehr and Schmidt 1999; Frohlich, Oppenheimer, and Kurki 2004). However, our knowledge of the existence and effects of social preferences in democratic decision making is still rather limited. In this article, we focus on the existence of social preferences in majority decision making, which is arguably the most important mode of democratic decision making. We present results from laboratory experiments which show that individual behavior in majority decisions is mainly driven by self-interest and fairness.
Recent theoretical developments demonstrate that the further development of democratic theory profits from paying more attention to the actual shape of preferences. For instance, Tyran and Sausgruber (2006) study individuals voting over redistribution. Their model predicts failure of redistributive policies if all players are exclusively egoistically motivated. However, employing a utility function from the Fehr and Schmidt (1999) model, which assumes that individuals are both self-interested and inequality averse, Tyran and Sausgruber (2006) analytically demonstrate that even a weak concern for equality can lead to the adoption of redistributive policies.

Frohlich and Oppenheimer (2007) have developed a formal model which demonstrates that, even in genuine distributional problems, cyclic majorities can be overcome if individuals hold sufficiently strong social preferences. Frohlich and Oppenheimer assume a societal shared conception of justice without specifying what justice concretely is. Individuals are upset by injustice and experience it as a cost. There is thus a possible trade-off between material self-interest and justice. Individuals are assumed to be heterogeneous in their evaluation of that

Jan Sauermann is a doctoral student at the International Max Planck Research School on the Social and Political Constitution of the Economy (IMPRS-SPCE), University of Cologne, Department of Political Science, P.O. Box 4110 20, 50870 Cologne, Germany (jan.sauermann@uni-koeln.de). André Kaiser is Professor of Political Science, University of Cologne, P.O. Box 411020,50870 Cologne, Germany (andre.kaiser@uni-koeln.de).

We thank Jens Grosser for his invaluable advice on the experimental design. We further thank Rebecca Morton, Bernhard Kittel, and Wolfgang Luhan for comments on earlier versions of this article and Ulrich Glassmann for his assistance in the laboratory. Suggestions of the journal's editor and several anonymous referees were particularly helpful to improve the article. Financial support from the Max Planck Institute for the Study of Societies and from the German Research Foundation (DFG) for the Cologne Laboratory for Economic Research is also gratefully acknowledged.

American Journal of Political Science, Vol. 54, No. 3, July 2010, Pp. 667-685 
trade-off. Individuals decide by majority rule whether to stick with a just status quo or redistribute income, which will result in a more unjust distribution. For the status quo to be stable, the evaluation of the trade-off of the voter who holds the median position concerning the strength of justice preferences is decisive. If her marginal costs from an increase in injustice exceed her marginal gains in utility from additional income, the status quo will remain stable. Frohlich and Oppenheimer show that the critical value of the strength of the median justice preferences necessary to avoid voting cycles depends heavily on the assumed utility function.

Overall, both models clearly show that in the discussion of normative contents of democratic decisions, the actual shape of preferences deserves as much attention as the formal properties of the aggregation mechanism. In this article, we argue that our present knowledge about the concrete motivations of individuals in majority decisions is incomplete. In the following section, we will review the existing experimental literature on majority decision making. The findings allow the conclusion that both self-interest and social preferences are guiding motivational factors of individual behavior. Existing results do not allow precise statements about the actual shape of the social preferences. From our point of view, however, such knowledge is essential to judge the content of democratic decisions. Earlier experiments also do not control for the conditions of information and communication between subjects. Hence, we cannot simply reanalyze existing experimental data in order to gain deeper insights in individual motivations. In the third section, we therefore develop a modified experimental design which corrects these shortcomings and allows us to differentiate between several explanations concerning the nature of social preferences. Our findings presented in the fourth section show that the ERC model by Bolton and Ockenfels (2000) best organizes our experimental results. We therefore identify self-interest and self-centered fairness as the most important motivational factors in majority decision making. In the last section, we discuss the main findings and their implications for future research.

\section{Experimental Evidence of Majority Decision Making}

Laboratory experiments provide for an excellent method to empirically investigate individual motivations in voting games. Due to real-world complexity, an empirical test with field data bears the major problem that it is hardly possible to control for all possible causal influ- ences. These factors can be controlled in the lab. Making payoffs dependent on the selected alternative, individual preferences can be induced through the payoff functions (Smith 1976).

For the sake of brevity, we refrain from presenting an extensive literature review on experimental majority decision making. ${ }^{1}$ We rather exemplify the gap addressed in this article using an example from an experiment conducted by Eavey and Miller (1984). In that experiment, three players had to select one out of ten alternatives labeled A-J by majority rule. Compared to spatial games with an infinite number of available alternatives, games like this containing a discrete set of alternatives provide the simplest setting for an experimental test of alternative models of individual behavior because possibly competing theoretical predictions can be presented to the participants as clearly distinguishable alternatives.

The payout table employed in series III of Eavey and Miller's experiments contains a nonempty core (alternative E). The selection of the core results in a relatively unequal distribution of payoffs ranging from $\$ 19.60$ for player 1 to $\$ 2.65$ for player 3. However, there is also alternative G, which promises $\$ 12.20$ to every player. Eight out of ten committees selected alternative $G$ and only two selected the predicted equilibrium E. Eavey and Miller interpret the result as indicating "a distinct preference for the voluntary imposition of unanimous coalitions around an alternative, in this case option G, which offers something for everyone" $(1984,579)$. They therefore argue that a combined concern for consensus and equity considerations cause deviations from the predicted equilibrium. They further argue that there is a trade-off between material self-interest and these social preferences. In their experiment, fairness is relatively cheap to obtain for player 2 , because player 2 only sacrifices $\$ 0.25$ voting for $G$ instead of E. In a similar experiment by Isaac and Plott (1978), one player has to forego $\$ 7.00$ to vote for the alleged fair alternative. In that experiment, fairness is more expensive and thus accounts for only five deviations from the core in 12 experimental runs.

We do not question the plausibility of Eavey and Miller's (1984) interpretation of the results. However, it is not the only possible explanation. Alternative $G$ has several other properties which could have led to its selection. ${ }^{2}$ It yields, for example, the highest sum of payoffs of all alternatives. Additionally, its minimal individual

\footnotetext{
${ }^{1}$ For overviews see, for example, McKelvey and Ordeshook (1990), Palfrey (2006), or Wilson (2007), as well as the references cited therein.

${ }^{2}$ It is not our intention to criticize Eavey and Miller for not having addressed all possible alternative explanations. We are aware of the fact that some of our concerns have been partially addressed
} 
payoff of $\$ 12.20$ is the highest minimal payoff of all 10 alternatives. Thus, we cannot rule out that a concern for the overall social welfare, maximin preferences, or a combination of both caused the deviations from the core. The results are also compatible with different kinds of equity preferences. On the one hand, the findings could indicate that individuals have a preference for global equality with an equal payout for all players. On the other hand, the committee decisions are also consistent with a concept of self-centered fairness where individual utility decreases if the personal payout deviates from the mean payout (see Bolton and Ockenfels 2000). On the basis of a three-player game, both conceptions of fairness cannot be differentiated.

While all rival explanations presented so far argue that social preferences cause the deviations from the predicted equilibrium, there are further possible interpretations of the findings. Option $G$ promises all players the same monetary payoff, and it is the only alternative in the upper half of the preference orders of all players. Both attributes make alternative $G$ prominent and thus a possible focal point in a complex coordination problem (Schelling 1960). Salant and Goodstein (1990) developed yet another theory, which changes the predicted committee choice from the single core alternative to a "selection set" by considering transaction costs of voting. Salant and Goodstein assume that the core fails if the resulting loss of the outcome compared to the core is less than a certain threshold $t \geq 0$ for every member of the winning coalition. ${ }^{3}$ Deviations from the core are costly to the majority of the committee. Salant and Goodstein argue that these costs are offset by transaction costs. These costs are independent of the resulting distribution. ${ }^{4}$ In the Eavey and Miller (1984) experiment above, $t=\$ 0.25$. Hence, alternative $G$ is well inside the selection set calculated by Salant and Goodstein (1990) on the basis of 45 experiments with varying payoff tables. Using maximum likelihood procedures, they estimate a threshold of $\$ 1.20$.

Overall, we argue that perfect rationality and egoistic self-interest alone cannot explain behavior in democratic decisions. We also see complex interactions between selfinterest and social preferences in the data. The findings suggest that equality or fairness considerations play an important role in distributional problems. Ceteris paribus, core alternatives guaranteeing an equal distribution of

in earlier studies. We have chosen the study by Eavey and Miller because it is the most suitable way to illustrate the competing models of behavior tested in this study in a concise way.

${ }^{3}$ If $t=0$, the selection set only comprises the core.

${ }^{4}$ See Bräuninger (2007) for a model of committee decision making which incorporates the same basic idea. payoffs are selected more frequently. If the payoff structure creates a trade-off between self-interest and fairness, the core's success shrinks. ${ }^{5}$ However, as we have shown, there are also other possible interpretations of the results. A differentiation between these possible interpretations of the actual shape of individual preferences is further complicated by the given opportunities of communication and the distribution of information between subjects in the experiment. In most experiments, including Eavey and Miller (1984), subjects only get ordinal information about other players' payoffs, but no information about the exact monetary values of the alternatives for the other players. Subjects interact face-to-face in these experiments. Although communication about monetary values is prohibited, subjects might be able to exchange additional information through their gestures, their facial expressions, or their accentuation. Thus, the actual level of information in the experiments is unknown. But without knowing the players' level of information it is almost impossible to derive unambiguous findings about the nature of their preferences. In the following section, we therefore develop a modified experimental design which corrects these shortcomings by the implementation of complete information about payoffs between subjects. This allows for a comparison of the explanatory power of several models of behavior in majority decision-making games.

\section{Experimental Design and Hypotheses}

Our design is tied to the existing experimental research on majority decision making with some modifications permitting the analysis of individual motivations in majority decision making. We study five-person committees that decide by majority rule over tables containing eight alternatives labeled A-H (all tables can be found in the appendix). Each subject has one vote, and all committee members cast their vote simultaneously. To reach a decision, at least three subjects have to vote for the same

\footnotetext{
${ }^{5}$ Similar patterns are apparent in spatial committee decisionmaking games. Eavey (1991) adopts the same experimental procedure including the same ordinal preferences configuration as in the seminal study by Fiorina and Plott (1978), but manipulates the cardinal payoffs, decreasing the slope of the original payoff functions. This manipulation does not alter the prediction of the core because it is a solution resting solely on ordinal information. Her results, however, differ from the original results, indicating that individuals attempt interpersonal comparisons of cardinal payoffs. Reanalyzing the experimental results of Fiorina and Plott (1978), Eavey (1991) and Grelak and Koford (1997) find a trade-off between self-interest and fairness in the data. While there is a general tendency toward the core point, the influence of fairness considerations increases if the costs of fairness are relatively low.
} 
alternative. If no alternative gets at least three votes in the first ballot of a round, all committee members will receive information on how the other committee members have just voted and a new ballot will be held. This procedure is repeated until an alternative receives a majority of votes. Hence, a single committee decision can consist of several ballots.

Our voting procedure differs from the one employed by Eavey and Miller (1984). Under their procedure, committee members may propose any alternative. If the proposal passes a majority vote, it becomes the committee's choice. If it fails, the floor is open for new proposals. Moreover, the committee can also decide to adjourn without a choice. In that case a predetermined alternative serves as the status quo and is automatically declared as the committee's choice. We refrain from introducing a status quo in our committee decisions because this gives a special prominence to the designated alternative. Subjects might use the resulting distribution of points as a reference point, and the choice of the status quo might thus bias behavior during decision making. In order to avoid such biases, we decided on a voting procedure that assigns equal influence to all committee members and that avoids emphasizing specific alternatives.

The whole game is played over 20 rounds. Committee members are randomly matched out of groups of 10 participants at the beginning of a round. ${ }^{6}$ The composition of committees thus changes between rounds, but does not change within a given round. We induce preferences through payoff tables, whose composition will be explained in detail below. The tables specify the distribution of points all players earn if a given alternative is selected by the committee. Payoffs depend on the points earned during the experiment.

We argued above that the distribution of information and the conditions of communication in previous experimental studies prevent unambiguous inferences about individual preferences. Additionally, it is a well-known fact that face-to-face interaction has independent effects in experiments, for example on the willingness to cooperate in dilemma games (e.g., Ostrom 1998). Because of this, our experiments are designed to control the level of information and communication. We aim at creating a baseline design which can be modified in subsequent experiments to study the partial effect of these variables. In this initial study, however, we focus on the influence of social preferences in majority decision making. Subjects interact anonymously via a computer net-

${ }^{6}$ Subjects are not informed about the restriction of the matching procedure. Nevertheless, the composition of the committees changes every round, just as the subjects were told. work. We run the experiments using the software $\mathrm{z}$-Tree (Fischbacher 2007). At the beginning of a round, each subject is informed which column of the table contains the number of points the subject will earn if a given alternative is selected. The entire table is common knowledge. We provide subjects with cardinal information in this study. In order to concentrate on the analysis of individual motivations, we thus abstract from one of the main problems of real committee members who have to assess how others evaluate a particular motion. In our experimental design, every committee member knows the number of points she and the other players can earn. Nevertheless, the players are unaware of the identity of the other committee members. In combination with the random reshuffle of committees after each round, participants cannot build a personal reputation between rounds. Therefore, every committee decision mirrors a one-shot situation.

We invited the subjects via email using the Online Recruitment System ORSEE developed by Greiner (2004). The complete pool from which we recruited our participants comprised more than 2,500 registered subjects. Nearly all of them were students from the University of Cologne, the majority coming from the Faculty of Management, Economics, and Social Sciences. Hence, all of our participants ( 67 men and 53 women) were students, $70 \%$ of them students of economics, business administration, or related fields. On average, participants were approximately 24 years old.

The experimental sessions took place in the Cologne Laboratory for Economic Research. Overall, we conducted four sessions, two in August 2006 and two in July 2007, with 30 participants each. After arriving at the laboratory, the subjects were randomly assigned to $\mathrm{cu}-$ bicles where they read the instructions. Questions were answered privately. ${ }^{7}$ At the end of each session, three rounds were randomly drawn. Participants were privately paid $€ 0.25$ per point earned in these rounds. Including a show-up fee of $€ 2.50$, participants earned on average $€ 17.60$, with a standard deviation of $€ 3.33$. Each session lasted about 90 minutes.

\section{The Tables}

The tables set the monetary incentives in our experiments. We created two sets of tables. Set A consists of

\footnotetext{
${ }^{7}$ Instructions can be obtained from the authors upon request. The understanding of the instructions was tested with a questionnaire. Subjects displayed only minor misunderstandings, which could be clarified by the experimenters.
} 
18 different tables employed in sessions 1 and $2 .{ }^{8}$ Set B contains 20 tables for sessions 3 and 4 . The tables were played in random order with the two committees consisting of the same 10 persons throughout the experiment always playing the same table in a given round.

All our tables contain a unique core alternative under the assumption of rationally acting and egoistically motivated committee members. In this case, rational choice theory makes an unambiguous prediction about the outcome of each single majority decision in every round, namely the selection of the particular core alternative. By contrasting this prediction with the actual choices of the committees, it serves as an efficient platform from which to study human behavior in majority decisions (Schotter 2006). In order to be able to infer the actual shape of underlying preferences, our payoff tables are constructed in such a way that competing models of behavior make different predictions about the likelihood that the committee decision will deviate from the predicted core alternative.

Constructing the tables, it is not possible to put equal weights on the empirical test of all those concepts. We therefore opt for another strategy, and first focus on the ERC theory by Bolton and Ockenfels (2000). ERC stands for Equity, Reciprocity, and Competition, which are among the most important explanations for observed behavior in a vast variety of games studied in experimental economics. ERC organizes these seemingly different kinds of behavior as a common pattern and thus greatly contributes to the cumulative aggregation of knowledge in experimental economics. We therefore also regard it as a potential explanation for behavior in democratic decision making.

ERC models $n$-player games, with $i=1,2, \ldots, n$. Players are randomly drawn from the population and interact anonymously in the lab. ERC assumes that players are motivated by two interacting factors, their own absolute payoff and their own relative payoff, which compares their own payoff to the mean payoff. Inequality aversion or self-centered fairness is the driving force of social preferences (Bolton and Ockenfels 2008). Ceteris paribus, a player's utility decreases the more the player's own payoff deviates from the mean payoff. ERC inhibits a possible trade-off between narrow self-interest and the relative income, which players solve individually. ERC is rational choice theory, as players still maximize their expected utility in strategic interactions. The major innovation of ERC is the integration of other-regarding behavior in individual utility functions. In this study, we assume a utility function which closely mirrors the function used

${ }^{8}$ In sessions 1 and 2, Table A4 was used in rounds 3, 10, and 19. by Bolton and Ockenfels $(2000,173)$ to illustrate their theory:

$$
v_{i}\left(y_{i}, \sigma_{i}\right)=a_{i} \cdot y_{i}-b_{i}\left(\sigma_{i}-\frac{1}{n}\right)^{2}
$$

The relative payoff $\sigma_{i}$ of player $i$ equals $i$ 's nonnegative personal payoff $y_{i}$ divided by the total sum of payoffs $\left(\sigma_{i}=\frac{y_{i}}{\sum_{j=1}^{n} y_{j}}\right) . a_{i}$ is the weight of the absolute payoff, and $b_{i}$ is the weight of the relative payoff $\left(a_{i}, b_{i} \geq 0\right)$. Equation (1) describes the possible trade-off between the absolute and the relative payoff. The individual solution to this trade-off is characterized by the relation of $a_{i}$ and $b_{i}$. Without loss of generality, we normalize $a_{i}$ to 1 . If $b_{i}$ takes a value of 0 the individual is only motivated by its self-interest as standard economic theory assumes. The concern for equality increases with $b_{i}$. Ceteris paribus, utility decreases symmetrically the more the individual share of payoffs differs from the mean payoff. ${ }^{9}$

All our tables contain a core alternative under the assumption of purely material self-interested players with $b_{i}=0$. However, the tables differ in the stability of the induced equilibrium. We define the stability of the core as the interval $[0 ; x]$ from which $b_{i}$ can be drawn so that the original core alternative remains the predicted equilibrium.

Illustrating our idea, consider Table A2 in the appendix. We concentrate on player 2. If she holds $b_{2}=0$ her rank order simply corresponds to the number of points she can earn if a given alternative is selected by the committee. Her concern for the relative payout increases with $b_{2}$. Alternatives guaranteeing a number of points closer to the average then gain in attractiveness. Take, for example, alternatives A and D promising her 32 and 54 points, respectively. Presuming a purely egoistical motivation, she will prefer D over A. However, if we assume the utility function (1) and $b_{2}=250$, player 2 prefers A to D because her utility from A equals 28.40 and thus exceeds her utility from $\mathrm{D}$, which is 25.10 .

Hence, if $b_{2}$ increases, her rank order of alternatives changes as the simple example shows. As other players'

${ }^{9}$ Tyran and Sausgruber (2006), for example, use the Fehr and Schmidt (1999) model, which also models inequality-averse individuals. Taking the complete payout vector into account, absolute payoffs of all other players enter the individual utility functions directly. It thus employs a more egalitarian notion of fairness than the ERC model because a player's utility does not only depend on its own absolute and relative payout, but also on the distribution of payouts among the other players. As players assign different weights for positive and negative deviations from the payoffs of other players, two variables describe the trade-off between self-interest and fairness in the Fehr-Schmidt model. We decided to use ERC because this model applies a more parsimonious formulation of that trade-off. 


\begin{tabular}{|c|c|c|c|c|c|c|c|c|}
\hline Table & $\begin{array}{l}\text { Stability } \\
\text { of the } \\
\text { Core }\end{array}$ & $\begin{array}{l}\text { Rank Order } \\
\text { of the } \\
\text { Stability of } \\
\text { the Core }\end{array}$ & $\begin{array}{c}\text { Standard } \\
\text { Deviation } \\
\text { of the } \\
\text { Points of } \\
\text { the Core }\end{array}$ & $\begin{array}{c}\text { Number of } \\
\text { Alternatives } \\
\text { with a Lower } \\
\text { Standard } \\
\text { Deviation Than } \\
\text { the Core }\end{array}$ & $\begin{array}{l}\text { Loss } \\
\text { Index }\end{array}$ & $\begin{array}{l}\text { Number of } \\
\text { Alternatives } \\
\text { in the } \\
\text { Selection Set } \\
\text { with } t=4\end{array}$ & $\begin{array}{l}\text { Relation of the } \\
\text { Sum of Points } \\
\text { of the Core to } \\
\text { the Highest } \\
\text { Sum of Points } \\
\text { in the Tables } \\
\text { (in \%) }\end{array}$ & $\begin{array}{c}\text { Selection } \\
\text { of the Core } \\
\text { (in \%) }\end{array}$ \\
\hline $\mathrm{A} 1$ & 104 & 3 & 25.21 & 6 & 2 & 4 & & 0 \\
\hline $\mathrm{A} 2$ & 217 & 6 & 17.63 & 1 & 2 & 1 & & 33.33 \\
\hline A3 & 384 & 11 & 11.58 & 3 & 2 & 2 & & 50.00 \\
\hline A4 & 434 & 13 & 15.57 & 5 & 2 & 3 & & 97.22 \\
\hline A5 & 454 & 14 & 10.64 & 2 & 2 & 3 & & 83.33 \\
\hline A6 & 555 & 17 & 13.16 & 2 & 2 & 1 & & 100.00 \\
\hline A7 & 625 & 19 & 9.65 & 2 & 4 & 2 & & 50.00 \\
\hline A8 & 666 & 20 & 9.55 & 2 & 2 & 2 & & 83.33 \\
\hline A9 & 769 & 22 & 10.26 & 2 & 3 & 1 & & 58.33 \\
\hline A 10 & 909 & 24 & 12.70 & 4 & 7 & 0 & & 91.67 \\
\hline A11 & 999 & 25 & 6.16 & 0 & 2 & 2 & & 91.67 \\
\hline A12 & 1250 & 27 & 6.60 & 1 & 2 & 1 & & 100.00 \\
\hline A13 & 1666 & 30 & 9.86 & 1 & 2 & 2 & & 100.00 \\
\hline A14 & 2000 & 31 & 7.82 & 1 & 3 & 1 & & 91.67 \\
\hline A15 & 2500 & 32 & 9.86 & 1 & 3 & 1 & & 91.67 \\
\hline A16 & $\infty$ & 33 & 1.41 & 0 & 3 & 1 & & 66.67 \\
\hline A17 & $\infty$ & 33 & 2.28 & 0 & 6 & 0 & & 100.00 \\
\hline A18 & $\infty$ & 33 & 0 & 0 & 2 & 2 & & 83.33 \\
\hline B1 & 65 & 1 & 10.35 & 2 & 2 & 2 & 66.67 & 0 \\
\hline B2 & 100 & 2 & 10.56 & 4 & 2 & 2 & 60.00 & 5.56 \\
\hline B3 & 132 & 4 & 11.76 & 4 & 2 & 2 & 64.29 & 66.67 \\
\hline B4 & 187 & 5 & 25.21 & 5 & 2 & 4 & 66.67 & 0 \\
\hline B5 & 217 & 6 & 17.63 & 3 & 2 & 1 & 83.33 & 16.67 \\
\hline B6 & 248 & 8 & 15.57 & 6 & 2 & 3 & 83.33 & 83.33 \\
\hline B7 & 306 & 9 & 33.33 & 7 & 3 & 1 & 100.00 & 0 \\
\hline B8 & 366 & 10 & 22.90 & 6 & 2 & 2 & 85.71 & 33.33 \\
\hline B9 & 403 & 12 & 11.10 & 3 & 5 & 0 & 84.62 & 91.67 \\
\hline B10 & 454 & 14 & 10.64 & 3 & 4 & 1 & 66.67 & 91.67 \\
\hline B11 & 520 & 16 & 16.11 & 5 & 2 & 1 & 100.00 & 100.00 \\
\hline B12 & 555 & 17 & 9.49 & 4 & 2 & 3 & 76.92 & 50.00 \\
\hline B13 & 742 & 21 & 6.16 & 1 & 2 & 1 & 73.08 & 58.33 \\
\hline B14 & 841 & 23 & 12.23 & 3 & 10 & 0 & 100.00 & 100.00 \\
\hline B15 & 999 & 25 & 6.16 & 1 & 2 & 2 & 83.33 & 83.33 \\
\hline B16 & 1309 & 28 & 7.82 & 1 & 4 & 1 & 69.23 & 66.67 \\
\hline B17 & 1512 & 29 & 6.60 & 0 & 2 & 1 & 71.43 & 75.00 \\
\hline B18 & $\infty$ & 33 & 0 & 0 & 4 & 1 & 85.71 & 83.33 \\
\hline B19 & $\infty$ & 33 & 2.28 & 0 & 4 & 1 & 64.29 & 83.33 \\
\hline B20 & $\infty$ & 33 & 1.41 & 0 & 4 & 1 & 76.92 & 91.67 \\
\hline $\begin{array}{l}\text { Hypothesized } \\
\text { influence on } \\
\text { the selection } \\
\text { of the core }\end{array}$ & & + & - & - & + & - & + & \\
\hline
\end{tabular}


rank orders change as well, the ERC model may yield different equilibrium predictions with increasing $b_{i}$. To calculate the stability of a core alternative, we assume that all committee members hold the same $b_{i}$ (in the following we will drop the subscript whenever $b_{i}$ is identical for all committee members). Following this logic, the core of Table A2 possesses a stability of 217 . For $b \in[0 ; 217]$ alternative $\mathrm{D}$ is the predicted equilibrium. For $b \in[218 ; \infty[$ ERC predicts alternative A. Overall, the tables are constructed to obtain a large variance in the stability of the core alternatives. Column 2 of Table 1 provides an overview. Our sets comprise equilibria that remain stable over the whole domain of $b$ (e.g., Table A16) as well as highly unstable equilibria like Table B1, in which the original core alternative is only stable for $b \in[0 ; 65]$.

It is important to point out that we regard the stability of the core as an ordinal variable. Column 3 of Table 1 lists the rank orders of the stability of the core. Hence, we do not assume that the core of Table A15 is exactly twice as stable as the core of Table A12, for example. All we say is that the equilibrium of Table A15 is more stable than the equilibrium of Table A12. Through this, our results depend less on the concrete parameterization of our utility function. It is also important to note that absolute and relative payoffs have different scale units. Thus, $b_{i}=100$ cannot be straightforwardly interpreted as player $i$ valuing her relative payoff at 100 times her value of her absolute payoff.

The tables are constructed to meet further requirements. First of all, over the whole domain of $b$, there exists an ERC equilibrium. This equilibrium might change once as in Table A2 above or change repeatedly, while in other tables the same alternative remains stable over the whole domain of $b$. For any $b$ the respective equilibrium is unique.

As explained above, the stability of the core is calculated under the assumption that $b_{i}$ adopts the same value for all committee members. However, experiments provide evidence that individual social preferences differ in their intensity (e.g., Fischbacher, Gächter, and Fehr 2001). To check the robustness of our calculations, we conducted Monte Carlo simulations in which $b_{i}$ is drawn randomly for every committee member. We conducted 2,000 simulations for each table. ${ }^{10}$ For each table in our sets, more than $97 \%$ of the simulations yield an unambiguous equilibrium.

One important line of criticism on the ERC model was put forward by Engelmann and Strobel (2004), who argue that individual behavior is motivated by a combi-

${ }^{10}$ In 500 simulations each, $b_{i}$ is randomly drawn for each committee member from the intervals $[0 ; 1000],[0 ; 2000],[0 ; 3000],[0 ; 5000]$. nation of efficiency concerns, maximin preferences, and selfishness. In order to test this objection, our two sets of tables differ in one important aspect. In set $\mathrm{A}$, the total sum of points is held constant. The sum of points always equals 100 for all alternatives. In set $B$, the sum of points varies between alternatives. To maintain the comparability between sets, the total number of points of all alternatives is roughly the same in every table. The comparison of behavior under both sets of tables allows us to control for a possible concern for the maximization of social welfare. If participants are motivated by preferences for social welfare, they will maximize the sum of points of the whole committee.

\section{Hypotheses}

Although we have at first focused on ERC, we are also interested in the explanatory power of competing theories. In order to compare the performance of different theories, we contrast our experimental results with the predictions of traditional rational choice theory, i.e., the selection of the core in every single committee decision. Thus, the assumptions of rationally acting and egoistically motivated individuals serve as a baseline condition, and we assess the explanatory powers of ERC and competing theories by their ability to correctly predict deviations from the core.

Concerning ERC, our tables differ in the stability of the core. Column 3 of Table 1 lists the rank order of the stability of the core alternative with stability increasing in the rank. On the basis of ERC, we hypothesize that the probability of the selection of the core increases with its stability. Since we do not know the exact $b_{i}$ of every player $i$ in a committee, we do not make a precise prediction of the committees' choice. Instead, we argue probabilistically. Hence, if the core is only stable for a small interval from which $b$ can be drawn, there is a high probability that the committee members are sufficiently inequality averse such that their rank order over the eight alternatives changes and the committee chooses another alternative. Analogously, a core that remains stable over a wide interval of $b$ should attract even highly inequality-averse individuals.

Analyzing the ability to predict the core's success, other theories can be tested as well. Instead of being inequality averse, subjects might be motivated by a concern for global equality of payouts for all committee members. Column 4 of Table 1 lists the standard deviation of points of the core alternative. Column 5 contains the number of alternatives with a lower standard deviation than the standard deviation of the core alternative. The former 
influences the attractiveness of the core directly, while the latter describes the attractiveness of the core in relation to the other alternatives. If subjects are motivated by a concern for global equality, an increase of both variables will decrease the probability of the selection of the core.

The selection set of Salant and Goodstein (1990) considers costs of voting. Following their logic, the core is less likely to be selected if the selection of another alternative causes a loss of less than a threshold $t \geq 0$. Column 6 lists the lowest loss index of all alternatives except the core. The costs of selecting another alternative rather than the core increase with this variable. Therefore, we hypothesize that the probability of the selection of the core increases with the loss index. Column 7 contains the number of alternatives besides the core in the selection set of the threshold $t=4$ points. ${ }^{11}$ Following Salant and Goodstein, we hypothesize a negative influence. If there are more alternatives inside the selection set, the core's success should decrease.

While in table set A the total sum of points is 100 for all alternatives, the sum of points varies between the alternatives in the tables of set B. Column 8 of Table 1 contains a variable which expresses the degree to which the core alternative maximizes social welfare in the tables of set $\mathrm{B}$. We measure it as the relation of the total sum of points of the core alternative to the maximum sum of points of all alternatives in the table. We expect that the probability of the selection of the core increases if the core guarantees a high degree of social welfare.

Finally, Bianco et al. (2006) recently reexamined the results of experimental committee decisions in a policy space without a core. They show that $94 \%$ of the outcomes lie in the uncovered set. They also provide new supportive experimental evidence from five-player computermediated and 35-player paper-and-pencil committee decisions (Bianco et al. 2008). Our experiments also provide for a test of the claim of Bianco et al. $(2006,2008)$. The uncovered set equals the core if the core is nonempty (Miller 1980). This implies that with the uncovered set being a good prediction of majority decision making, we should find no clear patterns in the deviations from the selection of the core in our results. ${ }^{12}$

\footnotetext{
${ }^{11}$ We also calculated the selection sets for $t=2, t=6, t=8$, and $t=10$. These values are also near the threshold of $\$ 1.20$ calculated by Salant and Goodstein (1990). Being the best model among them, we only report the results for $t=4$.

${ }^{12}$ Additionally, we tested whether individuals might be motivated by maximin preferences, i.e., a desire to maximize the utility of the worst off in a group. We also analyzed whether committee members lack the computational abilities to compute the rational choice equilibrium of a majority decision and instead condition their decisions on heuristics and focal alternatives in the payout tables.
}

\section{Experimental Results}

During the four sessions, we observed 24 committees with changing compositions over 20 rounds and thus collected data from a total of 480 single-committee decisions. The last column of Table 1 lists the frequency of the selection of the core alternative per table. The success of the core varies between 0 and $100 \%$. Thus, there is considerable variance which deserves explanation. Overall, $69 \%$ of all committee decisions resulted in the selection of the core. Hence, $31 \%$ or 149 out of 480 decisions deviate from the predictions of traditional rational choice theory. In sessions 1 and 2, which used table set A, the core was selected in $78.3 \%$ of the decisions. Based on table set B, only $59.6 \%$ of the committees selected the core in sessions 3 and 4 . Obviously, committees had no problems reaching a decision. On average, committees needed only 2.14 ballots (standard deviation: 1.63) to settle on an alternative. We find a significant negative correlation between the number of rounds and the average number of ballots held in a round $(r=-0.431, \mathrm{p}=0.005)$. Hence, subjects learn to reach a decision more quickly as the experiment progresses. We cannot find evidence that the subjects wanted to reach a consensual decision. There were 423 decisions $(88.13 \%)$ implemented by a bare majority of three committee members.

In the foregoing section we introduced several competing theories relevant for committee decision making. The theories stress the influence of different properties of the tables on individual behavior. We begin the examination of validity of the different hypotheses by reporting bivariate correlations between these properties and the frequency of the selection of the core by tables.

Table 2 reveals that the bivariate correlations confirm our hypotheses for most of the behavioral models discussed above. Concerning ERC, we find a strong and highly significant correlation between the stability of the core and the selection of the core. As hypothesized, the positive coefficient indicates that the success of the core increases with its stability. Hence, the result supports the hypothesis that self-centered inequality aversion is an important motivational factor in committee decisions. But as in older studies of majority decision making, it is impossible to exclude all other possible explanations on the basis of these bivariate correlations. For instance, behavior could also be motivated by a concern for global equality of payoffs. The correlation coefficient of the standard deviation of the distribution of points of the core

None of these models, however, provides a superior explanation for our experimental results compared to ERC. We therefore choose to refrain from presenting the results in detail. 


\section{TABLE 2 Correlations of Selection of the Core and Properties of the Tables}

\begin{tabular}{|c|c|c|}
\hline & \multicolumn{2}{|c|}{ Selection of the Core } \\
\hline & $\begin{array}{l}\text { Correlation } \\
\text { Coefficient }\end{array}$ & $\begin{array}{l}\text { Significance } \\
\text { (2-tailed) }\end{array}$ \\
\hline \multicolumn{3}{|l|}{$E R C$} \\
\hline $\begin{array}{l}\text { Rank order of the stability of } \\
\text { the core }{ }^{\dagger}\end{array}$ & $0.563^{* * *}$ & 0.000 \\
\hline \multicolumn{3}{|l|}{ Global Equality } \\
\hline $\begin{array}{l}\text { Standard deviation of the } \\
\text { points of the core }\end{array}$ & $-0.589^{* * *}$ & 0.000 \\
\hline $\begin{array}{l}\text { Number of alternatives with } \\
\text { a lower standard deviation } \\
\text { than the core }\end{array}$ & $-0.454^{* * *}$ & 0.004 \\
\hline \multicolumn{3}{|l|}{ Selection Set } \\
\hline Loss index & $0.330^{* *}$ & 0.043 \\
\hline $\begin{array}{l}\text { Number of alternatives in } \\
\text { the selection set with } t=4\end{array}$ & $-0.421^{* * *}$ & 0.009 \\
\hline \multicolumn{3}{|l|}{ Social Welfare } \\
\hline $\begin{array}{l}\text { Relation of the sum of points } \\
\text { of the core to the highest } \\
\text { sum of points in the tables } \\
\text { (in \%) }\end{array}$ & 0.236 & 0.317 \\
\hline
\end{tabular}

** Statistically significant at the 0.05 level (two-tailed).

${ }^{* * *}$ Statistically significant at the 0.01 level (two-tailed).

†Spearman's rho. All others: Pearson’s correlation coefficient.

alternative and the frequency of the core selection are negative as hypothesized and highly significant. The same applies for the relation between the number of alternatives with a lower standard deviation than the distribution of points of the core alternative and the selection of the core. We also cannot reject Salant and Goodstein's (1990) selection set as a possible explanation. As predicted, the correlation of the loss index and the core's success is positive. Moreover, the core is selected less frequently if the number of alternatives besides the core in the selection set with a threshold of four points increases. Among the competing theories, only social welfare seems to be a poor explanation for behavior in majority decision making, as the correlation does not reach a commonly accepted level of significance.

Of course, bivariate correlations can only provide for a first assessment of the theories' predictive powers. In the following, we will report findings from multivariate regressions. In our experiments, subjects interacted over 20 rounds in five-person committees, which were randomly reshuffled after every round, out of groups of 10 participants. To account for the time dimension in the data and the clustering of committees in the 10-person groups, we specify the following two-way error components model:

$$
\begin{aligned}
& \operatorname{logit}\left(\operatorname{Pr}\left(\text { Core selection }_{\mathrm{l}, \mathrm{m}, \mathrm{n}}=1 \mid \sum_{1}^{k} x_{k, l, m, n}, \mu_{1, m}, \mu_{2, n}\right)\right) \\
& =\beta_{0}+\beta_{k} \sum_{1}^{k} x_{\mathrm{k}, \mathrm{l,m}, \mathrm{n}}+\mu_{1, m}+\mu_{2, n}
\end{aligned}
$$

Since our dependent variable - the selection of the core-is dichotomous, we will use logistic regressions. If committee $l$ consisting of subjects from group $m$ selected the core in round $n$, Core selection ${ }_{1, \mathrm{~m}, \mathrm{n}}$ equals 1 ; otherwise it is 0 . We insert two different types of independent variables in our regression models. The first type of variables comprises the table characteristics already tested in the bivariate correlations above. The variables of the second type are included in all regression models to control for the influences of individual characteristics of the committee members. For instance, some experimental studies find a gender effect, with men acting more selfishly than women (e.g., Eckel and Grossman 1998). We include the number of men among the committee members to control for this effect. We also include the number of students of economics or related fields in each committee in the regressions to test whether these students act more selfishly than their fellow students (see, e.g., Marwell and Ames 1981). Most of our subjects participated in earlier experiments, so experimental experience might also influence our results. Therefore, we included the number of subjects among the committee members who participated in at least five earlier experiments as an independent variable. The random part of the regression model comprises two random intercepts. The random intercept $\mu_{1, m}$ is shared by group $m$ across all rounds of the experiment, whereas the random intercept $\mu_{2, n}$ is shared by all groups in a given round $n$.

As described above, we regard stability of the core as an ordinal variable. This has the advantage that our results hold for any monotonic transformation of our parameterized ERC utility function (1). On the other hand, regression procedures cannot analyze ordinal independent variables directly, because any coding using a single variable will be treated like a cardinal variable. Therefore, we will apply a coding scheme proposed by Walter, Feinstein, and Wells (1987) consisting of dummy variables that preserve the ordinal structure of our independent variable core stability and produce interpretable results in the regression analyses.

Since the cores of some of our 38 tables are equally stable, there are only 29 ranks in the independent variable core stability. We can thus define up to 28 independent 
TABLE 3 Regression Models

\begin{tabular}{|c|c|c|c|c|c|c|}
\hline \multirow{2}{*}{$\begin{array}{l}\text { Dependent Variable: } \\
\text { Selection of the Core }\end{array}$} & \multicolumn{2}{|c|}{ ERC } & \multicolumn{2}{|c|}{ Global Equality } & \multicolumn{2}{|c|}{ Selection Set } \\
\hline & (1) & $(2)$ & (3) & (4) & (5) & $(6)$ \\
\hline \multicolumn{7}{|l|}{ Fixed Part } \\
\hline Stability217 & $\begin{array}{c}-1.52^{* * *} \\
(0.43)\end{array}$ & $\begin{array}{l}-1.51^{* * *} \\
(0.42)\end{array}$ & & & & \\
\hline Stability 403 & $\begin{array}{l}-1.62^{* * *} \\
(0.41)\end{array}$ & $\begin{array}{l}-1.60^{* * *} \\
(0.41)\end{array}$ & & & & \\
\hline Stability625 & $\begin{array}{c}0.55 \\
(0.48)\end{array}$ & $\begin{array}{c}0.51 \\
(0.48)\end{array}$ & & & & \\
\hline Stability 841 & $\begin{array}{r}-1.23^{*} \\
(0.68)\end{array}$ & $\begin{array}{r}-1.19^{*} \\
(0.68)\end{array}$ & & & & \\
\hline Stability999 & $\begin{array}{c}0.55 \\
(0.72)\end{array}$ & $\begin{array}{c}0.52 \\
(0.72)\end{array}$ & & & & \\
\hline Stability 1512 & $\begin{array}{c}-1.55 \\
(1.14)\end{array}$ & $\begin{array}{c}-1.51 \\
(1.13)\end{array}$ & & & & \\
\hline Stability2000 & $\begin{array}{c}1.52 \\
(1.11)\end{array}$ & $\begin{array}{c}1.50 \\
(1.11)\end{array}$ & & & & \\
\hline $\begin{array}{l}\text { Standard deviation of the points } \\
\text { of the core }\end{array}$ & & & $\begin{array}{l}-0.19^{* * *} \\
(0.04)\end{array}$ & $\begin{array}{c}-0.19^{* * *} \\
(0.04)\end{array}$ & & \\
\hline $\begin{array}{l}\text { Number of alternatives with a lower } \\
\text { standard deviation than the core }\end{array}$ & & & $\begin{array}{r}0.20^{*} \\
(0.12)\end{array}$ & $\begin{array}{c}0.19 \\
(0.12)\end{array}$ & & \\
\hline Loss index & & & & & $\begin{array}{l}0.36^{* * *} \\
(0.13)\end{array}$ & $\begin{array}{l}0.36^{* * *} \\
(0.13)\end{array}$ \\
\hline $\begin{array}{l}\text { Number of alternatives in the selection } \\
\text { set with } t=4\end{array}$ & & & & & $\begin{array}{c}-0.42^{* * *} \\
(0.16)\end{array}$ & $\begin{array}{c}-0.42^{* * *} \\
(0.16)\end{array}$ \\
\hline Number of men & & $\begin{array}{c}0.14 \\
(0.11)\end{array}$ & & $\begin{array}{c}0.10 \\
(0.13)\end{array}$ & & $\begin{array}{c}0.10 \\
(0.14)\end{array}$ \\
\hline Number of students of economics & & $\begin{array}{c}-0.11 \\
(0.14)\end{array}$ & & $\begin{array}{c}-0.07 \\
(0.14)\end{array}$ & & $\begin{array}{c}-0.07 \\
(0.15)\end{array}$ \\
\hline $\begin{array}{l}\text { Number of subjects with experimental } \\
\text { experience }\end{array}$ & & $\begin{array}{r}0.20^{*} \\
(0.12)\end{array}$ & & $\begin{array}{r}0.23^{*} \\
(0.13)\end{array}$ & & $\begin{array}{c}0.21 \\
(0.14)\end{array}$ \\
\hline Constant & $\begin{array}{l}1.89^{* * *} \\
(0.38)\end{array}$ & $\begin{array}{c}1.23 \\
(0.69)\end{array}$ & $\begin{array}{l}2.65^{* * *} \\
(0.36)\end{array}$ & $\begin{array}{l}1.88^{* * *} \\
(0.71)\end{array}$ & $\begin{array}{c}0.74 \\
(0.62)\end{array}$ & $\begin{array}{c}0.04 \\
(0.90)\end{array}$ \\
\hline Random Part & & & & & & \\
\hline $\begin{array}{l}\text { Residual standard deviation between } \\
\text { groups }\end{array}$ & 0.25 & 0.00 & 0.53 & 0.41 & 0.67 & 0.57 \\
\hline $\begin{array}{l}\text { Residual standard deviation between } \\
\text { rounds }\end{array}$ & 0.73 & 0.74 & 0.77 & 0.77 & 0.97 & 0.97 \\
\hline Log likelihood & -218.61 & -216.40 & -245.67 & -243.80 & -257.99 & -256.54 \\
\hline
\end{tabular}

* Statistically significant at the 0.1 level (two-tailed).

*** Statistically significant at the 0.01 level (two-tailed).

Standard errors in parentheses.

dummy variables to describe the differences between the strata. These variables are labeled Stability65 to Stability2500. Illustrating the coding scheme, consider variable Stability65, which indicates whether ERC predicts an al- ternative different from the core alternative for all $b>65$ $(0=n o$ and $1=y e s)$. The core in Table B1 is the only one which fulfills this condition, because our ERC model predicts another alternative for all $b>65$. The core of 
Table B2 is stable up to $b=100$, so its value for stab65 is 0 . Analogously, we can define a dummy variable for every $b$ a core alternative gets unstable. If the core remains stable over the whole domain of $b$, all dummies for the table have a value of 0 . In the regressions presented in Table 3, we include seven dummies dividing the whole domain of $b$ into eight intervals. ${ }^{13}$ The coefficient of Stability $X$ corresponds to the log odds ratio between the level $\mathrm{X}$ and the next higher strata included in the model. For instance, the coefficient of Stability403 in Model 1 corresponds to the change of the probabilities of the selection of the core between Stability403 and Stability625. A negative coefficient thus indicates a decreasing probability of the selection of the core if its stability decreases from $b=625$ to $b=403$. On the basis of our ERC model we predict that the probability of the selection of the core increases monotonically with its stability. If our hypothesis is true, all significant coefficients of the dummies will have negative signs.

Table 3 reports regression results of the competing theories of individual behavior. We discuss two regression models for each theory. The first comprises only the variables describing the characteristics of the payout tables relevant for the given theory. The second model adds the individual characteristics of the committee members as independent variables.

We begin our discussion of the regression results with the ERC model. The results are largely in accordance with our hypotheses. All significant coefficients of the dummy variables are negative. In Model 1, which does not include individual characteristics of the committee members, we find three significant increases in the probability of the selection of the core. The coefficients of Stability 217 and Stability 403 are negative and highly significant, whereas the coefficient of Stability 841 is also negative, but only weakly significant. As all significant coefficients are negative, we can infer that the probability of the selection of the core increases monotonically with the core's stability.

Compared to the first model, the inclusion of individual characteristics of the committee members in the second model hardly affects the coefficients of the stability dummies. Only one of the individual properties has an influence on the selection of the core. We find a weakly significant positive influence of experimental experience. The probability of the selection of the core increases if the number of subjects who participated in at least five earlier experiments increases as well. However, we find

\footnotetext{
${ }^{13}$ The range of the intervals increases. The interval $b \in[0 ; 999]$ is divided into five parts of roughly equal size, while the interval $b \in$ [1000; 2000] is divided into two parts. The last interval comprises all tables with a core remaining stable for $b>2000$.
}

no significant gender effect, and behavior of students of economics or related fields is not distinguishable from the behavior of their fellow students. Adding individual characteristics into the models should decrease the unexplained variance between groups and, indeed, the comparison of the random part of Models 1 and 2 shows that this is the case. The residual standard deviation between groups decreases, while the residual standard deviation between rounds remains constant. We find a similar pattern in the regression models of the other two tested theories.

ERC clearly outperforms global equality as an explanation of behavior in majority decision making. The coefficient of the standard deviation of the core alternative is negative and highly significant in both Models. Regression Models 3 and 4 thus confirm the hypothesis that the probability of the selection of the core decreases if the distribution of points of the core alternative becomes more unequal. The second hypothesis, however, can be rejected. Contrary to the theory's predictions, in Model 3 the probability of the core selection increases with the number of alternatives with a lower standard deviation than the core alternative. Although the effect is not significant in Model 4, the coefficient of the number of alternatives with a lower standard deviation than the core still has the wrong sign. Furthermore, the log likelihood of the global equality models is considerably lower than in the ERC models, indicating a poorer model fit of the global equality models compared to the ERC models.

In both models testing the selection set, the coefficients have the expected sign. The coefficient of the loss index is positive and highly significant, indicating that an increase of the index raises the probability of the selection of the core alternative. However, the success of the core decreases significantly if the number of alternatives in the selection set defined by a threshold of four points increases. The regression results thus confirm the thesis that individuals consider costs of voting. Voters regard the predicted rational choice equilibrium as more attractive if the costs of choosing another alternative increase. However, the model fit of ERC clearly exceeds the model fit of the selection set. The log likelihood of both models testing the selection set is even lower than the log likelihood of the global equality models.

Overall, ERC is the best model of behavior in majority decisions among the models tested in the regression analyses. Especially for low values of $b$, ERC predicts deviations from the core well. The regression models thus highlight the important role of inequality aversion in majority decision making. At the same time, the bivariate correlations discussed above cannot identify influences of 
concerns for social welfare on individual behavior. This finding is confirmed when we take a closer look at the outcomes of sessions 3 and 4 . Out of the 240 decisions on the basis of table set B, 157 resulted in the selection of an alternative yielding exactly the sum of points as the core alternative. Fifty times an alternative with a higher sum of points was selected, and 33 committees chose an alternative with fewer points. We compare this distribution to a hypothetical distribution with the same number of outcomes resulting in the selection of an alternative with the same number of points as the core but an equal number of outcomes for the two other categories. We compare both distributions with a $\mathrm{X}^{2}$ test. $\mathrm{X}^{2}$ equals 3.482 with 2 degrees of freedom. The two-tailed p-value equals 0.1754 . Hence, we find no statistically significant difference between both distributions and thus no significant influence of a concern for social welfare.

Our findings also cast doubt on the uncovered set as a good prediction of the outcomes of majority decisions in games without a core (Bianco et al. 2006, 2008). If the core is nonempty, the uncovered set equals the core. We find clear nonrandom patterns in the deviations from the selection of the core- $\mathrm{a}$ fact the uncovered set cannot explain.

To ensure comparability of the findings, so far we have focused on the theories' abilities to predict the selection of the core correctly. To judge a theory's validity, however, it is equally important whether it predicts the actual outcomes correctly. In this respect, ERC also shows a good performance. In 451 out of 480 decisions, the committees selected an alternative predicted by the simulations with an identical $b_{i}$ for all committee members. Thirteen additional outcomes are possible ERC equilibria with individually varying weights of the relative payoffs. A precise assessment of the predicted power of the ERC model relies, of course, on $b$. Not all of the 464 decisions would be consistent with ERC if the exact value of $b$ was known. However, for each of the 451 decisions that resulted in the selection of an alternative predicted by the simulations with an identical $b$ for all committee members, we can narrow the interval from which $b$ has to be drawn to obtain the actual decision. For instance, remember Table A2 used above to illustrate the ERC model. If the committee selects the core (alternative D), we can infer that $b \in[0 ; 217]$. The selection of alternative A implies $b \in[218 ; \infty[$. We subdivide the range of $b$ in 37 intervals whose boundaries correspond to the values of $b$ for which the predicted equilibrium changes in a simulation. For each of these intervals, we can compute the share of the 480 committee decisions consistent with ERC. The results are shown in Figure 1.
Again, we contrast the observed outcomes with the predictions of traditional rational choice theory. If $b=0$, the core and ERC both predict $69 \%$ of the committee decisions correctly. The dashed line indicates the success rate of the core. Figure 1 shows that for the interval $b \in[66 ; 434]$ ERC can explain some of the committee decisions not explained by the core. An ERC model assuming $b \in[367 ; 384]$ correctly predicts $77.1 \%$ of the experimental outcomes. This amounts to an increase of 8.1 percentage points in the predictive power compared to the traditional rational choice model. ERC shows a superior predictive power only in a relatively small interval of $b$. The core outperforms ERC for any $b \in[435 ; \infty[$. For $b>2500$, for example, the predictive power of the core exceeds ERC by 35.9 percentage points.

So how plausible is the assumption $b \in[66 ; 434]$ ? To answer this question, we assess the assumption's implications for behavior in the ultimatum game and the dictator game, for which broad experimental evidence exists. In the two-player ultimatum game the proposer divides a fixed amount of money $c$ between herself and the second player, the responder. Afterwards the responder decides whether to accept or reject the proposed distribution. If she accepts, the proposal is implemented. Otherwise both get zero (Güth, Schmittberger, and Schwarze 1982). Contrary to exclusively self-interested players who would accept any positive offer as responders, inequality-averse individuals might reject positive offers from the proposers. At a certain threshold $s_{i}(c)$ player $i$ is indifferent between accepting a positive monetary amount yielding a relative payout below the mean and rejecting the offer, which would result in a payout of zero, which equals exactly the mean payout. Applying equation (1), the threshold $s_{i}(c)$ is implicitly defined by

$$
v_{i}\left(c s_{i}, s_{i}\right)=v_{i}(0,1 / n)
$$

Assuming $b=375$, which is almost in the middle of the interval $b \in[367 ; 384]$, and $c=€ 35$ (i.e., 140 points in our experiment), ${ }^{14} s_{i}(c)$ equals 0.216 . Hence, responders decline any offer below $€ 7.56$. This is consistent with behavior typically found in the ultimatum game, where responders reject the majority of small offers around $20 \%$ of the distributable amount (Camerer 2003, 34).

The dictator game offers an additional possibility to test the plausibility of concrete values of $b$. The dictator game is similar to the ultimatum game, with the only exception being that the responder lacks any veto power

\footnotetext{
${ }^{14}$ Subjects gained on average $€ 17.60$ for their participation in our experiment. This corresponds to $c=€ 35$ in the two-player ultimatum game.
} 


\section{FIGURE 1 Predictive Power of the ERC Model over the Range of $b$}

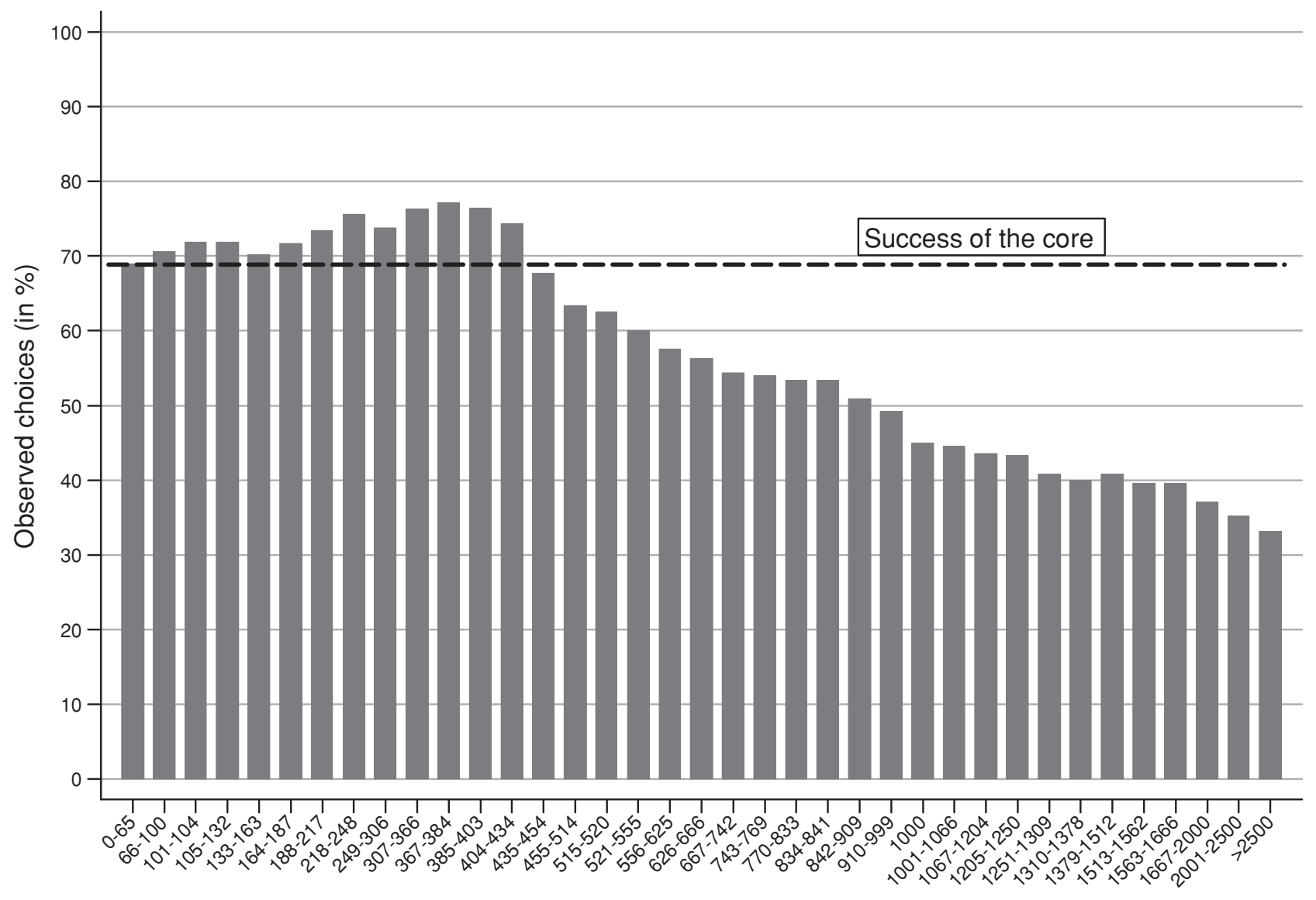

Weight of the relative payoff (b)

(e.g., Forsythe et al. 1994). Hence, the proposer will keep the share $r_{i}(c)$ of $c$ which maximizes her utility function (1). It thus follows:

$$
r_{i}(c)=\underset{\sigma_{i}}{\arg \max } v_{i}\left(c \sigma_{i}, \sigma_{i}\right)
$$

For the parameters $\stackrel{\sigma_{i}}{b}=375$ and $c=€ 35, r_{i}(c)$ equals 0.687, which implies that proposers in the dictator game keep $€ 24.03$ of the $€ 35.00$ for themselves and allocate $€ 10.87$ (31.3\%) to the other players. Camerer (2003, 57-58) reports results from 28 dictator game experiments in which mean offers vary between $10 \%$ and $52 \%$ of the distributable amount. The median value is $23 \%$, which is reasonably close to our own estimation. Hence, the concrete parameterization of our ERC model, which best predicts behavior of committees in majority decisions, also makes predictions in line with common experimental finding in ultimatum games and dictator games.

Overall, this fact underlines that social preferences play an important role in committee decision making.
Among the models tested, ERC is unequivocally the best explanation of our data. Hence, we confidently infer that self-interest and self-centered fairness motivate behavior in democratic decision making.

\section{Conclusion}

In this study, we have examined behavior in majority decision making. Traditional rational choice theory, assuming rationally acting individuals who are exclusively motivated by individual self-interest, cannot explain all outcomes in committee decision-making games. We therefore test the abilities of several competing behavioral models to explain the divergent outcomes. Overall, for the range of $b$ that is consistent with behavior in ultimatum and dictator games, our experiments show that ERC is the best explanation of our data among the models tested. Hence, we infer that the consideration of social preferences considerably adds explanatory power to 
rational choice-based predictions of behavior in majority decisions. Both self-interest and self-centered fairness motivate individual behavior in democratic decision making.

We understand this study as an initial exploratory work with the aims, first, to explore the existence of otherregarding preferences in majority decisions systematically and, second, to provide for a baseline condition from which to experimentally study subsequent problems of democratic decision making. Of course, further generalizations require replication and further experimentation. First of all, we need to know more about the strength of the individual social preferences. This asks for an experimental design that ideally first elicits the concrete values of $b_{i}$ held by individual subjects. This information can then be used to parameterize the ERC model. Such a model yields unique predictions of the committees' choices, which can be used to put the ERC model to a more rigorous test. ${ }^{15}$ Additionally, our results lead to new questions, such as how social preferences interact with other institutions like agenda-setting power in democratic decisions or how incomplete information affects behavior. Moreover, while we focused on the final outcomes of the committee decisions, subsequent work will also have to focus on the dynamics leading to the outcomes of committee decision making.

Of course, the external validity of the laboratory findings of our present study is too limited to provide for definite answers about the nature and the influence of social preferences in real democratic decisions. Nevertheless, our findings can offer hints of promising paths for the further development of democratic theory.

For instance, recent theoretical developments by Frohlich and Oppenheimer (2007) and Mackie (2003)

\footnotetext{
${ }^{15}$ Developing such a design accounting for the exact values of $b_{i}$ is certainly critical for the future use and applicability of ERC in further experiments and applied work. A possible solution to control for $b_{i}$ is to run an experiment in which subjects first play a dictator game to elicit the strength of individual social preferences. This information could then be used to parameterize the ERC model and test whether its predictions are consistent with actual behavior in a succeeding committee decision-making experiment.
}

established the insight that restrictions in the individual preference structures might avoid the arbitrariness of democratic decision procedures. Similarities of individual preference rankings and the existence of social preferences can restrict preference orders in such a way that voting cycles are theoretically possible, yet empirically rare. The crucial question is whether the restrictions imposed by social preferences are sufficiently strong to guarantee a majority decision without voting cycles. Frohlich and Oppenheimer (2007) demonstrate that the critical value of the strength of the social preferences necessary to avoid voting cycles depends on the actual shape of the utility function. Although we study preference configurations generating a core where the occurrence of cyclic majorities is not possible, our results shed light on the concrete nature of nonselfish behavior. A motivation by self-centered fairness implies that individuals have an egoistic perspective on justice, because they only value their own attained level of justice. The critical value is higher if individuals have an egoistic rather than an impartial perspective on justice, taking into account all injustices in society. Hence, it is important to consider that our results do not prove the critics of democratic aggregation mechanisms wrong. The existence of social preferences does not guarantee an unambiguous outcome in majority decisions. A fair outcome might simply not be available or the social preferences might be too weak to influence the outcomes so that cyclic majorities are still theoretically possible under majority rule.

Our findings allow for additional conclusions. One important finding concerns the role of social welfare. Our experimental findings indicate that the maximization of social welfare is not a major concern in majority decisions. Subjects do not care about maximizing group welfare directly, yet they do care about the fairness of the distribution of welfare. This is of major importance for institutional engineers. New institutions that theoretically create Pareto improvements compared to a given status quo might fail in practice if the resulting distribution increases inequality. Our experiments show that the problems of maximizing group welfare and distributing welfare are interconnected. 


\begin{tabular}{|c|c|c|c|c|c|c|c|c|c|c|c|c|c|c|c|}
\hline \multirow[b]{2}{*}{ Alternative } & \multicolumn{5}{|c|}{ Player } & \multicolumn{5}{|c|}{ Player } & \multicolumn{5}{|c|}{ Player } \\
\hline & 1 & 2 & 3 & 4 & 5 & 1 & 2 & 3 & 4 & 5 & 1 & 2 & 3 & 4 & \\
\hline & \multicolumn{5}{|c|}{ Table A1 } & \multicolumn{5}{|c|}{ Table A2 } & \multicolumn{5}{|c|}{ Table A3 } \\
\hline A & 7 & 28 & 35 & 22 & 8 & 13 & 32 & 19 & 15 & 21 & 10 & 50 & 21 & 2 & \\
\hline B & 2 & 8 & 12 & 77 & 1 & 39 & 5 & 4 & 6 & 46 & 17 & 24 & 22 & 15 & \\
\hline C & 5 & 41 & 24 & 4 & 26 & 62 & 16 & 2 & 11 & 9 & 19 & 13 & 30 & 12 & \\
\hline D & 58 & 2 & 17 & 19 & 4 & 15 & 54 & 8 & 18 & 5 & 5 & 30 & 48 & 6 & \\
\hline E & 45 & 1 & 8 & 1 & 45 & 1 & 1 & 14 & 2 & 82 & 21 & 4 & 18 & 17 & \\
\hline $\mathbf{F}$ & 10 & 3 & 70 & 5 & 12 & 5 & 13 & 57 & 21 & 4 & 14 & 28 & 16 & 8 & \\
\hline G & 8 & 10 & 66 & 6 & 10 & 3 & 9 & 43 & 42 & 3 & 1 & 18 & 3 & 71 & \\
\hline $\mathbf{H}$ & 21 & 49 & 21 & 3 & 6 & 9 & 10 & 1 & 64 & 16 & 4 & 45 & 9 & 3 & \\
\hline \multirow[t]{2}{*}{ Equilibrium } & \multicolumn{5}{|c|}{$\begin{array}{c}\mathrm{F}:[0-104], \mathrm{G}:[105-163] \\
\mathrm{A}:[164-\infty], M C: \mathrm{C}, \mathrm{H}\end{array}$} & \multicolumn{5}{|c|}{$\mathrm{D}:[0-217], \mathrm{A}:[218-\infty], M C: \mathrm{F}$} & \multicolumn{5}{|c|}{$\begin{array}{c}\text { E:[0-384], C:[385-833], } \\
\text { B: }[834-\infty]\end{array}$} \\
\hline & \multicolumn{5}{|c|}{ Table A4 } & \multicolumn{5}{|c|}{ Table A5 } & \multicolumn{5}{|c|}{ Table A6 } \\
\hline A & 28 & 7 & 27 & 9 & 29 & 24 & 9 & 7 & 49 & 11 & 20 & 23 & 16 & 23 & \\
\hline B & 4 & 43 & 3 & 45 & 5 & 2 & 5 & 41 & 3 & 49 & 50 & 17 & 13 & 7 & 13 \\
\hline C & 16 & 27 & 15 & 25 & 17 & 6 & 28 & 9 & 33 & 24 & 18 & 3 & 10 & 17 & \\
\hline D & 23 & 15 & 25 & 13 & 24 & 11 & 23 & 5 & 17 & 44 & 1 & 48 & 41 & 8 & \\
\hline E & 35 & 1 & 32 & 1 & 31 & 13 & 15 & 23 & 29 & 20 & 46 & 10 & 17 & 12 & 1 \\
\hline $\mathbf{F}$ & 11 & 31 & 13 & 33 & 12 & 4 & 52 & 16 & 10 & 18 & 4 & 24 & 40 & 25 & \\
\hline G & 9 & 39 & 8 & 37 & 7 & 44 & 11 & 20 & 12 & 13 & 28 & 12 & 18 & 10 & \\
\hline $\mathbf{H}$ & 21 & 19 & 20 & 21 & 19 & 35 & 13 & 28 & 15 & 9 & 12 & 20 & 8 & 55 & \\
\hline
\end{tabular}

Equilibrium

$$
\text { E:[0-434], A:[435-769], }
$$$$
\text { D:[770-2000], H:[2001- } \infty]
$$

Table A7

$\begin{array}{lrrrrr}\text { A } & 42 & 13 & 7 & 5 & 33 \\ \text { B } & 8 & 28 & 31 & 24 & 9 \\ \text { C } & 6 & 35 & 21 & 32 & 6 \\ \text { D } & 3 & 40 & 17 & 38 & 2 \\ \text { E } & 17 & 21 & 25 & 20 & 17 \\ \text { F } & 24 & 8 & 10 & 12 & 46 \\ \text { G } & 34 & 10 & 14 & 15 & 27 \\ \text { H } & 57 & 6 & 12 & 10 & 15\end{array}$

Equilibrium B:[0-625], E:[626- - ], MC: C
C:[0-454], E:[455- $\infty$ ], MC:

$\mathrm{D}, \mathrm{H}$

Table A8

$$
\text { A:[1001- } \infty]
$$

Table A9

$\begin{array}{rrrrrrrrrr}14 & 43 & 4 & 6 & 33 & 10 & 8 & 10 & 59 & 13 \\ 16 & 4 & 43 & 36 & 1 & 17 & 40 & 38 & 3 & 2 \\ 11 & 11 & 11 & 11 & 56 & 23 & 20 & 20 & 19 & 18 \\ 20 & 20 & 20 & 20 & 20 & 7 & 5 & 13 & 42 & 33 \\ 32 & 26 & 12 & 24 & 6 & 22 & 37 & 33 & 5 & 3 \\ 18 & 1 & 32 & 47 & 2 & 8 & 7 & 9 & 38 & 38 \\ 8 & 7 & 9 & 71 & 5 & 30 & 27 & 28 & 8 & 7 \\ 23 & 17 & 25 & 22 & 13 & 13 & 10 & 15 & 36 & 26\end{array}$

E:[0-666], H:[667-2000], D: $[2001-\infty]$

Table A11

\begin{tabular}{|c|c|c|c|c|c|c|c|c|c|c|c|c|c|c|}
\hline A & 20 & 20 & 20 & 20 & 20 & 20 & 45 & 7 & 16 & 12 & 9 & 61 & 14 & 11 \\
\hline B & 17 & 15 & 25 & 39 & 4 & 41 & 6 & 3 & 44 & 6 & 26 & 24 & 26 & 13 \\
\hline $\mathrm{C}$ & 15 & 11 & 18 & 41 & 15 & 5 & 34 & 8 & 1 & 52 & 15 & 10 & 18 & 15 \\
\hline D & 56 & 23 & 5 & 4 & 12 & 24 & 26 & 12 & 25 & 13 & 39 & 20 & 9 & 1 \\
\hline $\mathbf{E}$ & 12 & 18 & 27 & 26 & 17 & 17 & 24 & 21 & 20 & 18 & 16 & 7 & 45 & 5 \\
\hline $\mathbf{F}$ & 10 & 65 & 22 & 1 & 2 & 3 & 4 & 63 & 3 & 27 & 4 & 13 & 38 & 38 \\
\hline G & 28 & 8 & 1 & 50 & 13 & 15 & 16 & 15 & 18 & 36 & 12 & 2 & 10 & 23 \\
\hline $\mathbf{H}$ & 31 & 30 & 3 & 6 & 30 & 13 & 37 & 37 & 12 & 1 & 21 & 22 & 22 & 19 \\
\hline Equilibrium & \multicolumn{5}{|c|}{$\mathrm{H}:[0-909], \mathrm{A}:[910-\infty]$} & \multicolumn{5}{|c|}{ 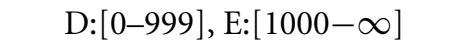 } & \multicolumn{4}{|c|}{ B:[0-1250], H:[1251- $\alpha$} \\
\hline
\end{tabular}

Table A12 


\begin{tabular}{|c|c|c|c|c|c|c|c|c|c|c|c|c|c|c|c|c|c|}
\hline \multirow[b]{2}{*}{ Alternative } & \multicolumn{5}{|c|}{ Player } & & \multicolumn{5}{|c|}{ Player } & & \multicolumn{5}{|c|}{ Player } \\
\hline & 1 & 2 & 3 & 4 & 5 & & 1 & 2 & 3 & 4 & 5 & & 1 & 2 & 3 & 4 & 5 \\
\hline & \multicolumn{5}{|c|}{ Table A13 } & \multicolumn{7}{|c|}{ Table A14 } & \multicolumn{5}{|c|}{ Table A15 } \\
\hline A & 12 & 1 & 54 & 28 & 5 & 12 & 1 & 54 & 28 & 5 & 12 & 1 & 54 & 28 & 5 & 12 & 1 \\
\hline B & 32 & 25 & 17 & 16 & 10 & 32 & 25 & 17 & 16 & 10 & 32 & 25 & 17 & 16 & 10 & 32 & 25 \\
\hline C & 62 & 4 & 15 & 10 & 9 & 62 & 4 & 15 & 10 & 9 & 62 & 4 & 15 & 10 & 9 & 62 & 4 \\
\hline D & 21 & 6 & 29 & 32 & 12 & 21 & 6 & 29 & 32 & 12 & 21 & 6 & 29 & 32 & 12 & 21 & 6 \\
\hline E & 11 & 35 & 2 & 4 & 48 & 11 & 35 & 2 & 4 & 48 & 11 & 35 & 2 & 4 & 48 & 11 & 35 \\
\hline F & 8 & 46 & 7 & 36 & 3 & 8 & 46 & 7 & 36 & 3 & 8 & 46 & 7 & 36 & 3 & 8 & 46 \\
\hline G & 15 & 19 & 10 & 9 & 47 & 15 & 19 & 10 & 9 & 47 & 15 & 19 & 10 & 9 & 47 & 15 & 19 \\
\hline $\mathbf{H}$ & 10 & 43 & 14 & 13 & 20 & 10 & 43 & 14 & 13 & 20 & 10 & 43 & 14 & 13 & 20 & 10 & 43 \\
\hline \multirow[t]{2}{*}{ Equilibrium } & \multicolumn{5}{|c|}{ 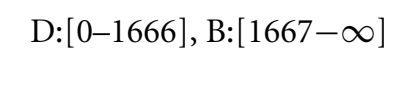 } & \multicolumn{7}{|c|}{ 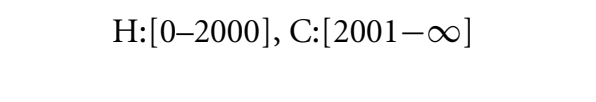 } & \multicolumn{5}{|c|}{$\begin{array}{c}\mathrm{D}:[0-2500], \mathrm{B}:[2501-\infty], \\
M C: \mathrm{E}\end{array}$} \\
\hline & \multicolumn{5}{|c|}{ Table A16 } & \multicolumn{7}{|c|}{ Table A17 } & \multicolumn{5}{|c|}{ Table A18 } \\
\hline A & 19 & 33 & 7 & 35 & 6 & 19 & 33 & 7 & 35 & 6 & 19 & 33 & 7 & 35 & 6 & 19 & 33 \\
\hline B & 7 & 13 & 31 & 5 & 44 & 7 & 13 & 31 & 5 & 44 & 7 & 13 & 31 & 5 & 44 & 7 & 13 \\
\hline $\mathrm{C}$ & 22 & 21 & 18 & 20 & 19 & 22 & 21 & 18 & 20 & 19 & 22 & 21 & 18 & 20 & 19 & 22 & 21 \\
\hline D & 8 & 8 & 39 & 7 & 38 & 8 & 8 & 39 & 7 & 38 & 8 & 8 & 39 & 7 & 38 & 8 & 8 \\
\hline $\mathbf{E}$ & 10 & 14 & 33 & 8 & 35 & 10 & 14 & 33 & 8 & 35 & 10 & 14 & 33 & 8 & 35 & 10 & 14 \\
\hline $\mathbf{F}$ & 12 & 44 & 1 & 40 & 3 & 12 & 44 & 1 & 40 & 3 & 12 & 44 & 1 & 40 & 3 & 12 & 44 \\
\hline G & 5 & 10 & 35 & 10 & 40 & 5 & 10 & 35 & 10 & 40 & 5 & 10 & 35 & 10 & 40 & 5 & 10 \\
\hline $\mathbf{H}$ & 15 & 35 & 3 & 37 & 10 & 15 & 35 & 3 & 37 & 10 & 15 & 35 & 3 & 37 & 10 & 15 & 35 \\
\hline Equilibrium & \multicolumn{5}{|c|}{ C: $[0-\infty]$} & \multicolumn{7}{|c|}{$\mathrm{E}:[0-\infty]$} & \multicolumn{5}{|c|}{$\mathrm{F}:[0-\infty]$} \\
\hline
\end{tabular}

A
B
C
D
E
F
G
H

Equilibrium G:[0-65], F:[66- $\infty$ ], MC: B

\section{Table B4}

$$
\begin{aligned}
& \text { A } \\
& \text { B } \\
& \text { C } \\
& \text { D } \\
& \text { E } \\
& \text { F } \\
& \text { G } \\
& \text { H }
\end{aligned}
$$

\section{Equilibrium}

Table B1

$\begin{array}{rrrrrr}35 & 28 & 8 & 5 & 4 & 35 \\ 26 & 9 & 24 & 20 & 1 & 26 \\ 4 & 5 & 21 & 13 & 62 & 4 \\ 3 & 3 & 46 & 15 & 43 & 3 \\ 77 & 1 & 2 & 1 & 14 & 77 \\ 21 & 13 & 17 & 31 & 33 & 21 \\ 5 & 15 & 19 & 34 & 7 & 5 \\ 29 & 61 & 11 & 17 & 2 & 29\end{array}$

Table B2

Table B3
Table B5

$\begin{array}{rrrrrr}12 & 8 & 77 & 1 & 2 & 12 \\ 17 & 2 & 18 & 4 & 29 & 17 \\ 25 & 20 & 20 & 8 & 7 & 25 \\ 8 & 1 & 1 & 95 & 45 & 8 \\ 70 & 3 & 5 & 12 & 10 & 70 \\ 44 & 10 & 8 & 10 & 8 & 44 \\ 15 & 43 & 3 & 6 & 13 & 15 \\ 24 & 33 & 4 & 24 & 5 & 24\end{array}$

\section{Table B6}

\begin{tabular}{|c|c|c|c|c|c|c|c|c|c|c|}
\hline 8 & 77 & 1 & 2 & 12 & 8 & 77 & 1 & 2 & 12 & 8 \\
\hline 2 & 18 & 4 & 29 & 17 & 2 & 18 & 4 & 29 & 17 & 2 \\
\hline 20 & 20 & 8 & 7 & 25 & 20 & 20 & 8 & 7 & 25 & 20 \\
\hline 1 & 1 & 95 & 45 & 8 & 1 & 1 & 95 & 45 & 8 & 1 \\
\hline 3 & 5 & 12 & 10 & 70 & 3 & 5 & 12 & 10 & 70 & 3 \\
\hline 10 & 8 & 10 & 8 & 44 & 10 & 8 & 10 & 8 & 44 & 10 \\
\hline 43 & 3 & 6 & 13 & 15 & 43 & 3 & 6 & 13 & 15 & 43 \\
\hline 33 & 4 & 24 & 5 & 24 & 33 & 4 & 24 & 5 & 24 & 33 \\
\hline \multicolumn{6}{|c|}{$\mathrm{C}:[0-217], \mathrm{H}:[218-\infty]$} & \multicolumn{5}{|c|}{$\begin{array}{c}\mathrm{G}:[0-248], \mathrm{C}:[249-1000], \\
\mathrm{D}:[1001-\infty]\end{array}$} \\
\hline
\end{tabular}




\begin{tabular}{|c|c|c|c|c|c|c|c|c|c|c|c|c|c|c|c|c|c|}
\hline \multirow[b]{2}{*}{ Alternative } & \multicolumn{5}{|c|}{ Player } & & \multicolumn{5}{|c|}{ Player } & & \multicolumn{5}{|c|}{ Player } \\
\hline & 1 & 2 & 3 & 4 & 5 & & 1 & 2 & 3 & 4 & 5 & & 1 & 2 & 3 & 4 & 5 \\
\hline & \multicolumn{5}{|c|}{ Table B7 } & \multicolumn{7}{|c|}{ Table B8 } & \multicolumn{5}{|c|}{ Table B9 } \\
\hline A & 46 & 5 & 4 & 6 & 39 & 46 & 5 & 4 & 6 & 39 & 46 & 5 & 4 & 6 & 39 & 46 & 5 \\
\hline B & 11 & 13 & 57 & 9 & 5 & 11 & 13 & 57 & 9 & 5 & 11 & 13 & 57 & 9 & 5 & 11 & 13 \\
\hline C & 5 & 94 & 8 & 18 & 15 & 5 & 94 & 8 & 18 & 15 & 5 & 94 & 8 & 18 & 15 & 5 & 94 \\
\hline D & 82 & 1 & 14 & 2 & 1 & 82 & 1 & 14 & 2 & 1 & 82 & 1 & 14 & 2 & 1 & 82 & 1 \\
\hline E & 16 & 20 & 1 & 64 & 9 & 16 & 20 & 1 & 64 & 9 & 16 & 20 & 1 & 64 & 9 & 16 & 20 \\
\hline $\mathbf{F}$ & 3 & 9 & 34 & 41 & 3 & 3 & 9 & 34 & 41 & 3 & 3 & 9 & 34 & 41 & 3 & 3 & 9 \\
\hline G & 20 & 30 & 18 & 15 & 12 & 20 & 30 & 18 & 15 & 12 & 20 & 30 & 18 & 15 & 12 & 20 & 30 \\
\hline $\mathbf{H}$ & 9 & 16 & 2 & 11 & 32 & 9 & 16 & 2 & 11 & 32 & 9 & 16 & 2 & 11 & 32 & 9 & 16 \\
\hline Equilibrium & \multicolumn{6}{|c|}{ 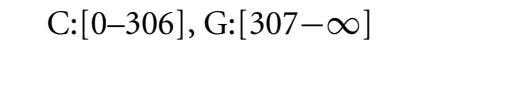 } & \multicolumn{6}{|c|}{ 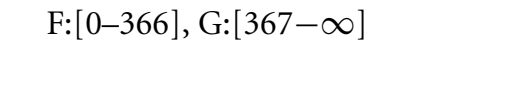 } & \multicolumn{5}{|c|}{$\begin{array}{c}\mathrm{D}:[0-403], \mathrm{A}:[404-1204], \\
\mathrm{F}:[1205-\infty]\end{array}$} \\
\hline
\end{tabular}

Table B10

A
B
C
D
E
F
G
H

Equilibrium$$
71
$$$$
4149
$$$$
434
$$$$
16 \quad 18
$$$$
924
$$

\section{$\begin{array}{lllllllll}14 & 9 & 13 & 31 & 18 & 14 & 9 & 13 & 31\end{array}$}

$$
\begin{array}{lllllllll}
23 & 20 & 15 & 13 & 29 & 23 & 20 & 15 & 13
\end{array}
$$$$
\begin{array}{lllll}
7 & 11 & 9 & 24 & 49
\end{array}
$$

$$
\text { G:[0-454], B:[455- } \infty \text { ] }
$$

Table B13

A
B
C
D
E
F
G
H
Equilibrium

$$
\begin{array}{rrrrr}
22 & 17 & 20 & 25 & 31 \\
57 & 53 & 8 & 8 & 4 \\
24 & 23 & 25 & 11 & 12 \\
1 & 5 & 28 & 43 & 8 \\
14 & 15 & 13 & 33 & 15 \\
10 & 20 & 31 & 13 & 6 \\
3 & 3 & 4 & 27 & 63 \\
18 & 13 & 45 & 1 & 43 \\
\text { C:[0-742], A: }[743-\infty]
\end{array}
$$

A
B
C
D
E
F
G
H
Equilibrium

$$
\mathrm{F}:[1563-\infty]
$$

Equilibrium
Table B14

\section{Table B12}

$\begin{array}{lllll}13 & 31 & 18 & 14 & 9\end{array}$

$\begin{array}{lllll}15 & 13 & 29 & 23 & 20\end{array}$

$\begin{array}{lllll}11 & 43 & 12 & 71 & 13\end{array}$

$\begin{array}{lllll}5 & 2 & 3 & 41 & 49\end{array}$

$\begin{array}{lllll}18 & 9 & 10 & 4 & 34\end{array}$

$\begin{array}{lllll}52 & 4 & 15 & 16 & 18\end{array}$

$\begin{array}{lllll}28 & 6 & 33 & 9 & 24\end{array}$

$\begin{array}{lllll}9 & 24 & 49 & 7 & 11\end{array}$

E:[0-555], A:[556- $\infty]$

Table B15
Table B16

Table B17

$$
\begin{array}{llllllll}
20 & 10 & 43 & 13 & 14 & 20 & 10 & 43
\end{array}
$$

$\begin{array}{llllllll}3 & 8 & 46 & 36 & 7 & 3 & 8 & 46\end{array}$

$\begin{array}{llllllll}37 & 6 & 26 & 4 & 2 & 37 & 6 & 26\end{array}$

$$
\begin{array}{llllllll}
14 & 17 & 6 & 27 & 26 & 14 & 17 & 6
\end{array}
$$

$\begin{array}{llllllll}10 & 32 & 25 & 16 & 17 & 10 & 32 & 25\end{array}$

$\begin{array}{lllll}5 & 12 & 1 & 30 & 32\end{array}$

$$
\begin{array}{lllll}
8 & 92 & 15 & 11 & 4
\end{array}
$$

E:[0-1309], F:[1310- $)$

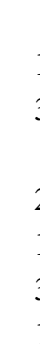
$13 \quad 14$

36

4

$27 \quad 26$

$16 \quad 17$

32

$92 \quad 15$

E:[0-1512], D:[1513- $)$,

MC: C
Table B18

$\begin{array}{llll}9 & 12 & 54 & 15\end{array}$ $\begin{array}{llll}13 & 14 & 20 & 10\end{array}$ $\begin{array}{llll}36 & 7 & 3 & 8\end{array}$ $\begin{array}{llll}4 & 2 & 37 & 6\end{array}$ $\begin{array}{llll}27 & 26 & 14 & 17\end{array}$ $\begin{array}{llll}16 & 17 & 10 & 32\end{array}$ $\begin{array}{llll}30 & 32 & 5 & 12\end{array}$ $\begin{array}{lll}4 & 8\end{array}$ C: $[0-\infty]$ 
APPENDIX Continued

\begin{tabular}{|c|c|c|c|c|c|c|c|c|c|c|c|c|c|c|c|}
\hline \multirow[b]{2}{*}{ Alternative } & \multicolumn{5}{|c|}{ Player } & \multicolumn{5}{|c|}{ Player } & \multicolumn{4}{|c|}{ Player } & \\
\hline & 1 & 2 & 3 & 4 & 5 & 1 & 2 & 3 & 4 & 5 & 1 & 2 & 3 & 4 & 5 \\
\hline & \multicolumn{5}{|c|}{ Table B19 } & \multicolumn{5}{|c|}{ Table B20 } & & & & & \\
\hline A & 1 & 37 & 3 & 52 & 7 & 33 & 35 & 14 & 10 & 8 & & & & & \\
\hline B & 7 & 67 & 11 & 6 & 49 & 37 & 53 & 16 & 8 & 6 & & & & & \\
\hline C & 42 & 26 & 6 & 10 & 1 & 46 & 40 & 8 & 2 & 14 & & & & & \\
\hline D & 14 & 6 & 38 & 39 & 13 & 15 & 30 & 10 & 5 & 10 & & & & & \\
\hline $\mathbf{E}$ & 51 & 9 & 15 & 1 & 4 & 1 & 4 & 57 & 16 & 52 & & & & & \\
\hline $\mathbf{F}$ & 3 & 16 & 43 & 8 & 10 & 2 & 8 & 28 & 14 & 28 & & & & & \\
\hline G & 26 & 14 & 13 & 12 & 55 & 6 & 6 & 30 & 18 & 30 & & & & & \\
\hline $\mathbf{H}$ & 18 & 20 & 21 & 16 & 15 & 18 & 19 & 21 & 22 & 20 & & & & & \\
\hline Equilibrium & \multicolumn{5}{|c|}{$\mathrm{H}:[0-\infty]$} & \multicolumn{5}{|c|}{$\mathrm{H}:[0-\infty]$} & & & & & \\
\hline
\end{tabular}

Note: Set A was used in sessions 1 and 2, set B in sessions 3 and 4 .

Table A4 was played in round 3. In rounds 10 and 19 of sessions 1 and 2, permutations of A4 were played, changing the labels of the alternatives but keeping the original dominance structure untouched.

MC: Additional ERC equilibria from the Monte Carlo simulations with randomly drawn $b_{i}$ for every committee member.

\section{References}

Bianco, William T., Michael S. Lynch, Gary J. Miller, and Itai Sened. 2006. “'A Theory Waiting to Be Discoverd and Used': A Reanalysis of Canonical Experiments on Majority Rule Decision-Making." Journal of Politics 68(4): 838-51.

Bianco, William T., Michael S. Lynch, Gary J. Miller, and Itai Sened. 2008. "The Constrained Instability of Majority Rule: Experiments on the Robustness of the Uncovered Set." Political Analysis 16(2): 115-37.

Bolton, Gary E., and Axel Ockenfels. 2000. "ERC: A Theory of Equity, Reciprocity, and Competition." American Economic Review 90(1): 166-93.

Bolton, Gary E., and Axel Ockenfels. 2008. "Self-Centered Fairness in Games with More Than Two Players." In Handbook of Experimental Economics Results, ed. Charles R. Plott and Vernon L. Smith. North Holland: Elsevier, 531-40.

Bräuninger, Thomas. 2007. "Stability in Spatial Voting Games with Restricted Preference Maximizing." Journal of Theoretical Politics 19(2): 173-91.

Camerer, Colin. 2003. Behavioral Game Theory: Experiments in Strategic Interaction. Princeton, NJ: Princeton University Press.

Charness, Gary, and Matthew Rabin. 2002. "Understanding Social Preferences with Simple Tests." Quarterly Journal of Economics 117(3): 817-69.

Eavey, Cheryl L. 1991. "Patterns of Distribution in Spatial Games." Rationality and Society 3(4): 450-74.

Eavey, Cheryl L., and Gary J. Miller. 1984. "Fairness in Majority Rule Games with a Core." American Journal of Political Science 28(4): 570-86.

Eckel, Catherine C., and Philip J. Grossman. 1998. “Are Women Less Selfish Than Men? Evidence from Dictator Experiments." Economic Journal 108(448): 726-35.

Engelmann, Dirk, and Martin Strobel. 2004. "Inequality Aversion, Efficiency, and Maximin Preferences in Simple
Distribution Experiments." American Economic Review 94(4): 857-69.

Fehr, Ernst, and Urs Fischbacher. 2002. "Why Social Preferences Matter-the Impact of Non-Selfish Motives on Competition, Cooperation and Incentives." Economic Journal 112(478): C1-C33.

Fehr, Ernst, and Klaus M. Schmidt. 1999. "A Theory of Fairness, Competition, and Cooperation." Quarterly Journal of Economics 114(3): 817-68.

Fiorina, Morris P., and Charles R. Plott. 1978. "Committee Decisions under Majority Rule: An Experimental Study." American Political Science Review 72(2): 575-98.

Fischbacher, Urs. 2007. "Z-Tree: Zurich Toolbox for ReadyMade Economic Experiments." Experimental Economics 10(2): 171-78.

Fischbacher, Urs, Simon Gächter, and Ernst Fehr. 2001. “Are People Conditionally Cooperative? Evidence from a Public Goods Experiment." Economics Letters 71(3): 397-404.

Forsythe, Robert, Joel L. Horowitz, N. E. Savin, and Martin Sefton. 1994. "Fairness in Simple Bargaining Experiments." Games and Economic Behavior 6(3): 347-69.

Frohlich, Norman, and Joe A. Oppenheimer. 2007. "Justice Preferences and the Arrow Problem." Journal of Theoretical Politics 19(4): 363-90.

Frohlich, Norman, Joe A. Oppenheimer, and Anja Kurki. 2004. "Modeling Other-Regarding Preferences and an Experimental Test.” Public Choice 119(1-2): 91-117.

Greiner, Ben. 2004. "An Online Recruitment System for Economic Experiments." In Forschung Und Wissenschaftliches Rechnen 2003. GWDG Bericht 63, ed. Kurt Kremer and Volker Macho. Göttingen: Gesellschaft für Wissenschaftliche Datenverarbeitung, 79-93.

Grelak, Eric, and Kenneth Koford. 1997. “A Re-Examination of the Fiorina-Plott and Eavey Voting Experiments: How Much Do Cardinal Payoffs Influence Outcomes?" Journal of Economic Behaviour and Organization 32(4): 571-89. 
Güth, Werner, Rolf Schmittberger, and Bernd Schwarze. 1982. "An Experimental Analysis of Ultimatum Bargaining." Journal of Economic Behaviour and Organization 3(4): 367-88.

Isaac, Mark R., and Charles R. Plott. 1978. "Cooperative Game Models of the Influence of the Closed Rule in Three Person, Majority Rule Committees: Theory and Experiment." In Game Theory and Political Science, ed. Peter C. Ordeshook. New York: New York University Press, 283-322.

Mackie, Gerry. 2003. Democracy Defended. Cambridge: Cambridge University Press.

Marwell, Gerald, and Ruth E. Ames. 1981. "Economists Free Ride, Does Anyone Else? Experiments on the Provision of Public Goods, IV." Journal of Public Economics 15(3): 295-310.

McKelvey, Richard D., and Peter C. Ordeshook. 1990. “A Decade of Experimental Research on Spatial Models of Elections and Committees." In Advances in the Spatial Theory of Voting, ed. James M. Enelow and Melvin J. Hinich. Cambridge: Cambridge University Press, 99-144.

Miller, Nicholas. 1980. "A New Solution Set for Tournament and Majority Voting." American Journal of Political Science 24(1): 68-96.

Ostrom, Elinor. 1998. "A Behavioral Approach to the Rational Choice Theory of Collective Action." American Political Science Review 92(1): 1-22.
Palfrey, Thomas R. 2006. "Laboratory Experiments in Political Economy." In The Oxford Handbook of Political Economy, ed. Barry R. Weingast and Donald Wittman. Oxford: Oxford University Press, 915-36.

Salant, Stephen W., and Eban Goodstein. 1990. "Predicting Committee Behavior in Majority Rule Voting Experiments." RAND Journal of Economics 21(2): 293-313.

Schelling, Thomas. 1960. The Strategy of Conflict. Oxford: Oxford University Press.

Schotter, Andrew. 2006. "Strong and Wrong: The Use of Rational Choice Theory in Experimental Economics." Journal of Theoretical Politics 18(4): 498-511.

Smith, Vernon L. 1976. "Experimental Economics: Induced Value Theory." American Economic Review 66(2): 274-79.

Tyran, Jean-Robert, and Rupert Sausgruber. 2006. "A Little Fairness May Induce a Lot of Redistribution in Democracy." European Economic Review 50(2): 469-85.

Walter, Stephen D., Alvan R. Feinstein, and Carolyn K. Wells. 1987. "Coding Ordinal Independent Variables in Multiple Regression Analyses." American Journal of Epidemiology 125(2): 319-23.

Wilson, Rick K. 2007. "Voting and Agenda Setting in Political Science and Economics." In Laboratory Experiments in the Social Sciences, ed. Murray Webster and Jane Sell. Amsterdam: Elsevier, 433-57. 